\title{
Modeling residential water and related energy, carbon footprint and costs in California
}

\author{
Alvar Escriva-Bou ${ }^{l, 2, *}$, Jay R. Lund ${ }^{l}$ and Manuel Pulido-Velazquez ${ }^{2}$ \\ 1. Center for Watershed Sciences, University of California, Davis. One Shields Avenue, \\ Davis, CA. 95616, USA. \\ 2. Research Institute of Water and Environmental Engineering, IIAMA, Universitat \\ Politècnica de València. Camí de Vera S/N, 46022 València, Spain.
}




\begin{abstract}
Starting from single-family household water end-use data, this study develops an end-use model for water-use and related energy and carbon footprint using probability distributions for parameters affecting water consumption in 10 local water utilities in California. Monte Carlo simulations are used to develop a large representative sample of households to describe variability in use, with water bills for each house for different utility rate structures.
\end{abstract}

The water-related energy consumption for each household realization was obtained using an energy model based on the different water end-uses, assuming probability distributions for hotwater-use for each appliance and water heater characteristics. Spatial variability is incorporated to account for average air and household water inlet temperatures and price structures for each utility. Water-related energy costs are calculated using averaged energy price for each location. $\mathrm{CO}_{2}$ emissions were derived from energy use using emission factors.

Overall simulation runs assess the impact of several common conservation strategies on household water and energy use. Results show that single-family water-related $\mathrm{CO}_{2}$ emissions are $2 \%$ of overall per capita emissions, and that managing water and energy jointly can significantly reduce state greenhouse gas emissions.

\title{
KEYWORDS:
}

California; carbon footprint; greenhouse emissions; residential water-use; water-energy nexus; water-energy conservation strategies. 





included to estimate irrigation necessities for outdoor use. Final results came from 2500 Monte Carlo household simulations ${ }^{1}$ for each utility.

\section{$2.3 \quad$ Water-Related Energy Model}

Our energy model only accounted for energy used by the household water heater because this is the main household water-related energy use. Energy used by the utility to procure water for the household can be estimated separately. So the first step was to obtain the hot water draws for water end-uses.

A few studies have analyzed household hot water-use patterns. We used a probability distribution of hot water draws from data by Mayer et al. (2003) on East Bay Municipal Utility District (details provided in Supporting Information).

With these hot water end-uses, water heater energy use was estimated using the WHAM equation (Lutz et al., 1998) defined as the summed energy content of hot water drawn from the heater plus energy expended to recover from standby losses.

(10) $Q_{\text {in }}=\frac{\mathrm{vol} \cdot \mathrm{den} \cdot C p \cdot\left(T_{\text {tank }}-T_{\text {in }}\right)}{\eta_{r e}} \cdot\left(1-\frac{U A \cdot\left(T_{\text {tank }}-T_{a m b}\right)}{P_{o n}}\right)+24 \cdot U A \cdot\left(T_{\text {tank }}-T_{a m b}\right)$

Being:

$\mathrm{Q}_{\text {in }}=\quad$ total water heater energy consumption (Btu/day)

$\eta_{\mathrm{re}}=\quad$ recovery efficiency

$\mathrm{P}_{\mathrm{on}}=\quad$ rated input power $(\mathrm{Btu} / \mathrm{hr})$

${ }^{1} 2500$ samples were taken because it was a relative large amount of samples to obtain consistent results — same main statistics — with different runs, and at the same time that keep a reasonable computational time. 


$$
\begin{array}{ll}
\mathrm{UA}= & \text { standby heat loss coefficient }\left(\mathrm{Btu} / \mathrm{hr} \cdot{ }^{\circ} \mathrm{F}\right) \\
\mathrm{T}_{\text {tank }}= & \text { thermostat setpoint temperature }\left({ }^{\mathrm{o}} \mathrm{F}\right) \\
\mathrm{T}_{\mathrm{in}}= & \text { inlet water temperature }\left({ }^{\circ} \mathrm{F}\right) \\
\mathrm{T}_{\mathrm{amb}}= & \text { temperature of the air around the water heater }\left({ }^{\circ} \mathrm{F}\right) \\
\mathrm{vol}= & \text { volume of water drawn in } 24 \text { hours }(\mathrm{gal} / \mathrm{day}) \\
\mathrm{den}= & \text { density of water }(\mathrm{lb} / \mathrm{gal}) \\
\mathrm{C}_{\mathrm{p}}= & \text { specific heat of water }\left(\mathrm{Btu} / \mathrm{lb} \cdot{ }^{\circ} \mathrm{F}\right)
\end{array}
$$

The WHAM equation includes the same three types of parameters used for the water end-use models: i) household technological characteristics of the water heater; ii) users' behaviors as the (setpoint temperature); iii) climatic data (temperature of the air and the inlet water temperature). Probability distributions of each parameter were derived from the Residential Energy Consumption Survey 2009 (EIA, 2009) for single-houses in California and from Energy Efficiency Standards for Water Heaters (DOE, 2009). Temperature and evapotranspiration parameter values are from the California Irrigation Management Information System (CIMIS).

Finally we obtained the water-related energy consumption for each of 2500 Monte Carlo simulated households for each of the 10 water utilities. We used the WHAM equation over the hot water volume computed from the water end-uses with probabilistic hot water percentages for each appliance. We also randomly sampled all parameters for each household water heater from their probability distributions.

\subsection{Carbon emissions}

From energy consumption $\mathrm{CO}_{2}$ emissions were calculated, accounting for the type of the energy used — electric or gas-fired water heaters — and the energy utility that provided it. 
The California Registry's Power/Utility Workgroup reports greenhouse emission factors for electric power generation, transmission and delivery (CRPUW, 2009). $\mathrm{CO}_{2}$ emissions ranged from $0.24 \mathrm{~kg} \cdot \mathrm{CO}_{2} / \mathrm{kWh}$ to $0.58 \mathrm{~kg} \cdot \mathrm{CO}_{2} / \mathrm{kWh}$ (complete $\mathrm{CO}_{2}$ emission factors for each utility are provided in the Supporting Information)

Roughly 85 percent of natural gas used in California is imported from the American Southwest, Rocky Mountains and Canada; the remaining 15 percent is produced in-state. The variability of emission factors from different sources is quite low, so we used the weighted national average of $5.31 \mathrm{~kg} \mathrm{CO}_{2} /$ therm (EIA, 2011).

\subsection{Water and Water-Related Energy Costs}

The water bill for each house was calculated using the water rate structure for each utility for 2006, the year of the California Single-Family Water Use Efficiency Study (DeOreo et al., 2011).

Regarding energy rates, we used an overall energy price for each utility. Electricity prices range from $\$ 0.105 / \mathrm{kWh}$ in LADPW to $\$ 0.166 / \mathrm{kWh}$ in San Diego Gas \& Electric. The natural gas price is $\$ 11.79$ per thousand cubic feet $(\$ 0.0115$ per thousand Btu) from the Energy Almanac of the California Energy Commission.

More details of water and energy rate structures are provided in the Supporting Information.

\section{$2.6 \underline{\text { Scenarios }}$}

Several simulations were run to analyze the effects of different scenarios - technological improvements, behavioral modifications, and an overall water-use reduction - on water and energy use, GHG emissions and water and water-related energy costs. Technological-based 
simulations were used to analyze potential impacts of command-and-control policies, behavioralbased simulations were run to analyze the effects of reductions for each behavioral parameter.

Technology improvements —retrofit toilet, retrofit shower, retrofit dishwasher, retrofit washing machine, substitution of natural turf for artificial turf or xeriscape, and installation of smart irrigation controllers - were simulated by changing technological parameter values from the initial probability distributions with a new probability distribution assuming that all appliances are retrofitted.

To simulate behavioral modifications - reductions in toilet flushes, shower length, shower frequency, bath frequency, leaks detection and fixing and stress irrigation-we assumed $10 \%$ reduction for each behavioral parameter to analyze which behavioral parameters have more impact on water and water-related energy use for each city.

On the energy side, we simulated the installation of a new water heater —using two types of electric and two types of natural gas commercial water heaters, one in the intermediate and other in the high range of efficiency ${ }^{2}$ values for each energy source- and a behavioral action to decrease the water heater setpoint temperature to $120^{\circ} \mathrm{F}$ for households that have a setpoint temperature above this value.

Finally, we simulated an overall water-use decrease of $10 \%$ for each household in order to analyze the differences among locations based on the heterogeneity of residential water and energy linkages that the model captures.

${ }^{2}$ High efficiency electric water heater is a heat pump water heater that can achieve an efficiency value of 2.2 , three times that of a common electric water heater. 


\section{RESULTS}

\subsection{Water End-Use Model}

The goodness of fit of the end-use model was formally tested using the Kolmogorov-Smirnov two-sample test (Smirnov, 1948) failing to reject in all the cases the null hypothesis that modeled and metered data have the same underlying distribution. Figure 2 shows an example comparison of the cumulative histograms for the results obtained with the water end-uses models and the real data metered in the city of Davis, with a p-value for the K-S two-sample test of 0.28.

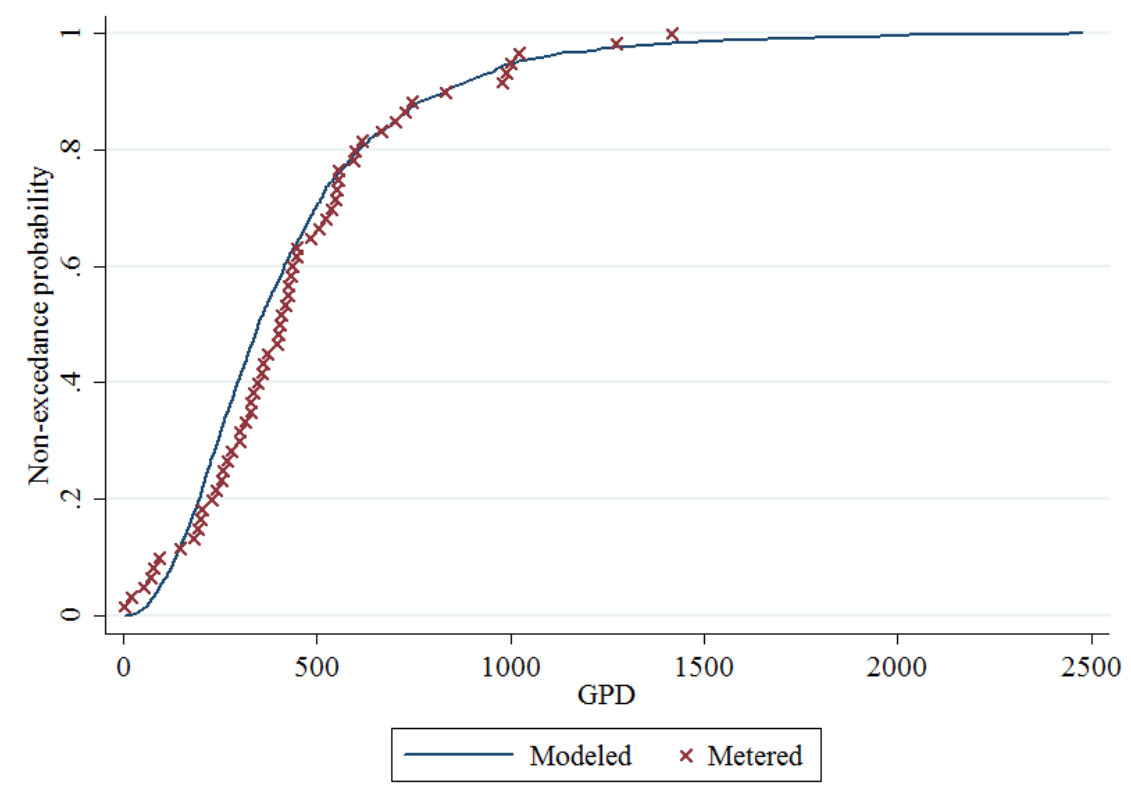

Figure 2: Comparison of the cumulative histograms for metered and modeled total water-use in Davis (as a sum of the end-use models).

\subsection{Water-Related Energy Model}

For water-related energy we compared the results of our model with a sample of 1088 singlefamily houses in California from the 2009 Residential Energy Consumption Survey (EIA, 2009). Even though the comparison of the descriptive statistics (Table 2) shows that the results differ 

Outdoor use is the largest water-use amounting to $\$ 44.3 /$ month (56\% of water costs and $47 \%$ of total cost). Shower $(8.2 \%$ of water costs and $13.1 \%$ of total costs) and faucet ( $8.5 \%$ of water costs and $13 \%$ of total costs) uses are second and third in cost because of high shares of hot water-use. Toilet, leaks/other, and clothes washer are less important although they use a similar amount of water than shower and faucet. Finally bath and dishwasher end-uses are only minor shares of the total uses, emissions and costs.

Notice that water and water-related energy costs are similar in energy-intensive end-uses such as faucet, shower, bath or dishwasher. 







action, whereas other cities could. Big differences on economic incentives depend on water and energy rates, ranging from Las Virgenes (low water rates and high consumption) to San Francisco (high water rates).

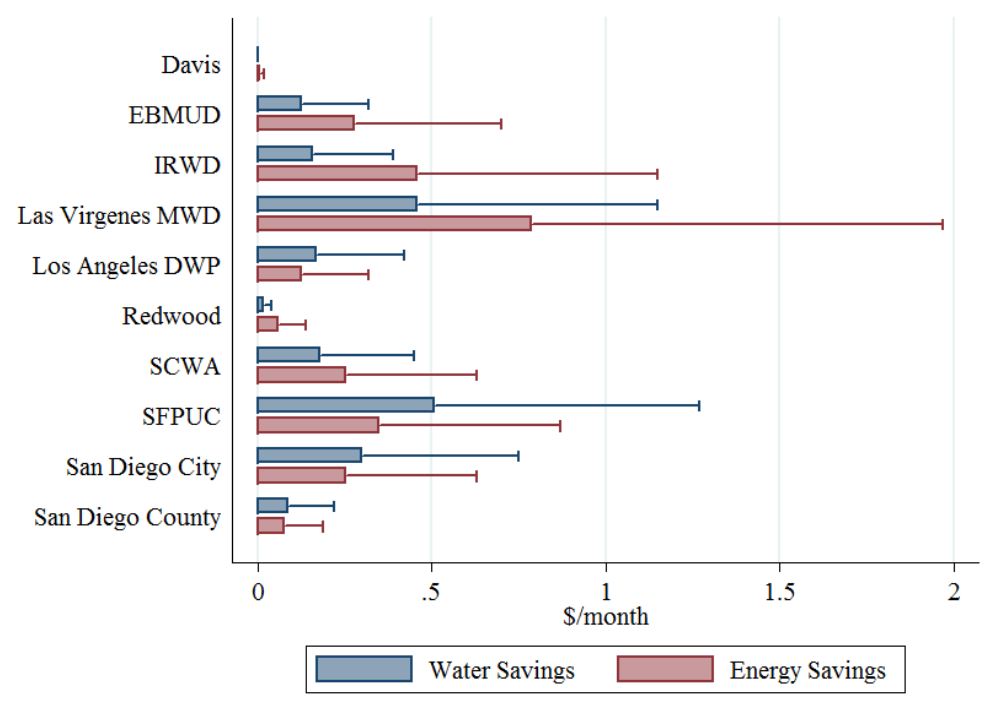

Figure 8: Economic savings from retrofitting shower per utility.

\section{- Targeting:}

A small proportion of households accounts for a disproportionate share of water and waterrelated energy use. A water utility that focuses attention on these high users - in the higher quartile of water and energy consumption - and using advanced metered technology available, can increase returns from conservation strategies considerably.

Taking the results from the $10 \%$ overall water reduction simulation for median users and the higher quartile of users, obtaining that in average water savings increase twice, energy and $\mathrm{CO}_{2}$ savings increase 2.4 times, and economic benefits for customers increase 2.3 times (Figure 9).

High-use customers should be more receptive to conservation measures because of their increased economic benefits, increasing the likelihood of conservation campaign success. The 

campaign with normal-use customers.

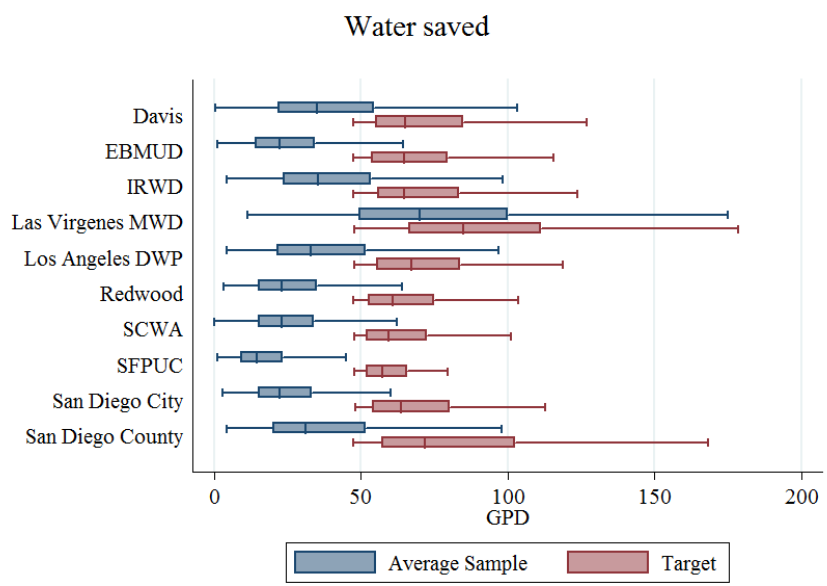

$\mathrm{CO}_{2}$ saved

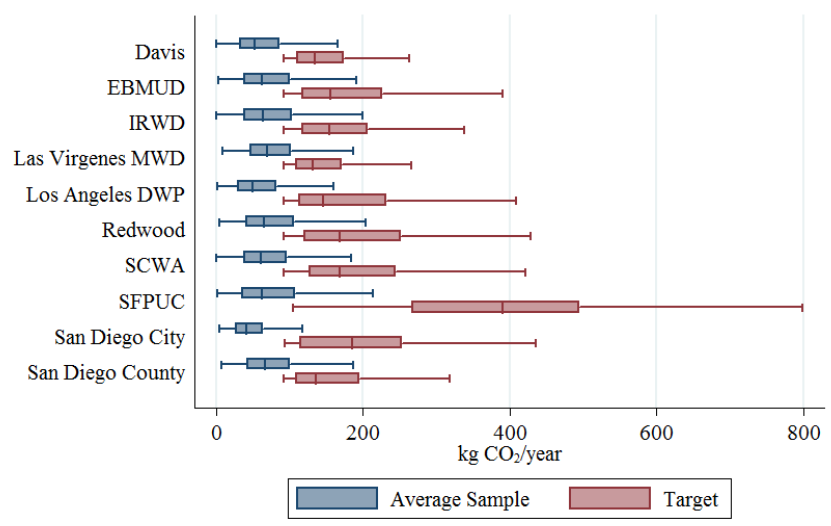

Energy saved

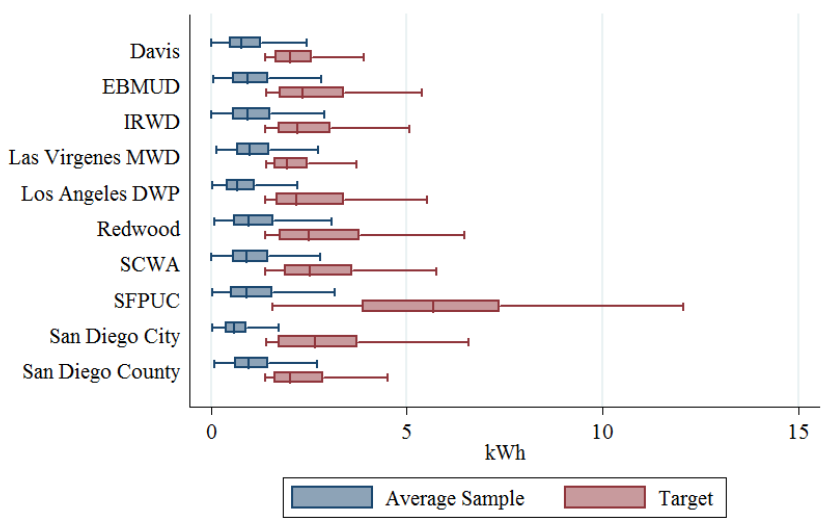

Economic savings

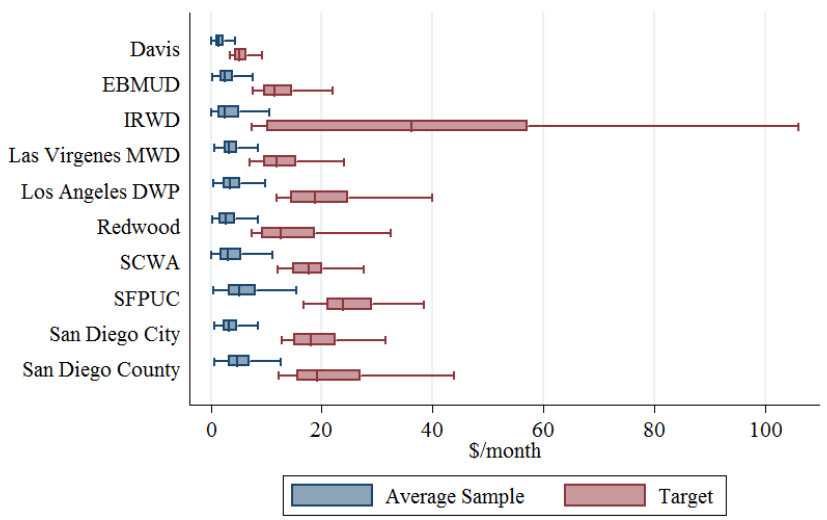

Figure 9: Comparison for water, water-related energy, $\mathrm{CO} 2$ emissions and costs reduction assuming a 10\% decrease in water-use between average users and targeting customers for each utility.

- Efficiency over the planning scales:

The efficiency of a conservation action depends on the planning objective. For example: the state of California could try to reduce the total amount of GHG emissions by retrofitting water heaters, installing new electric water heaters that have high efficiency with a $\mathrm{CO}_{2}$ reduction of $533 \mathrm{~kg} /$ year per household on average, whereas natural gas water heaters only reduce $105 \mathrm{~kg}$ 
$\mathrm{CO}_{2} /$ year per household (Figure 10). But if customers seek only to reduce their costs, electric water heaters will only be meaningful in Los Angeles (because of cheaper electric rates), whereas in every other location, lower natural gas rates will always overcome electric water heaters' energy costs.
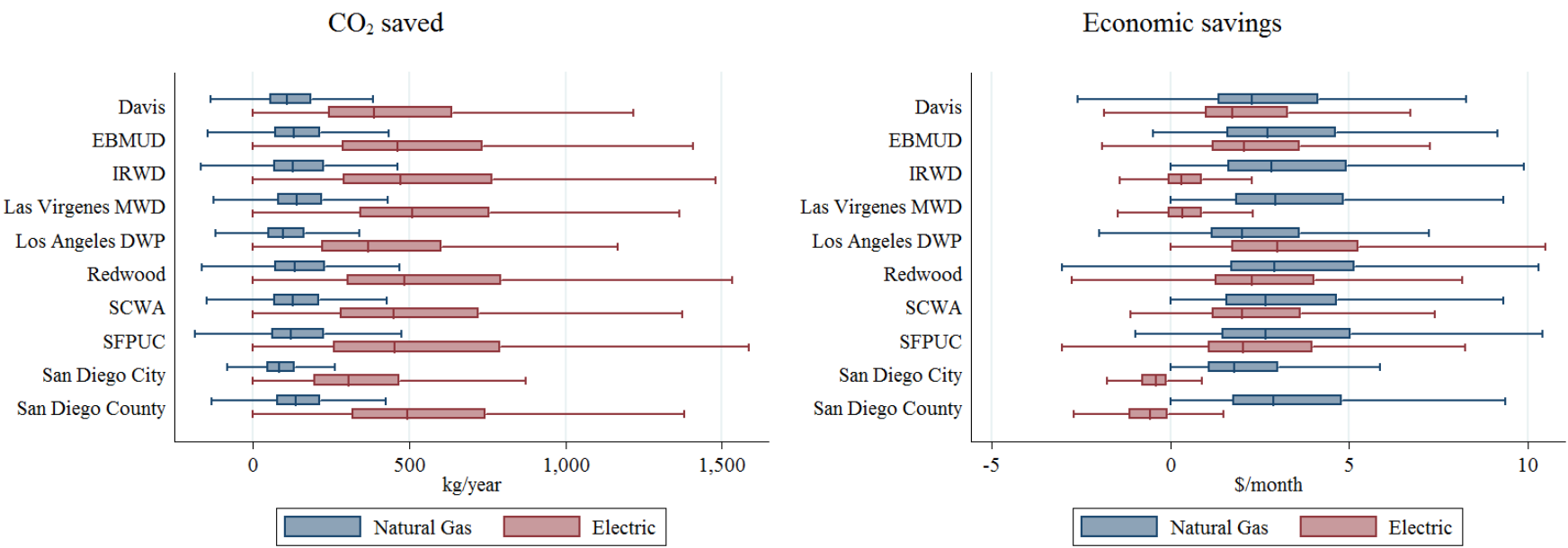

Figure 10: Comparison of $\mathrm{CO} 2$ and economic savings between gas-fired and electric water heater retrofitting per utility.

\section{DISCUSSION}

The water end-use model fits metered data well because the probability distributions were drawn from metered households, whereas we lack metered data to test the water-related energy end-use model, although the model results are close to the RECS results. Our results also are consistent with previous studies: water-related energy used was slightly higher than results of Abdallah and Rosenberg (2014), probably because we are including losses with the WHAM formulation, and slightly lower than those from Kenway et al. (2013) because we are not including energy used directly by appliances (although their results for total gas use, hot water + losses, are slightly lower than ours). 
Total water-use variability is driven by variability in outdoor water-use. Cheaper water rates and inland climates in Las Virgenes and Davis imply a high outdoor use, meanwhile relatively small lots in San Francisco cause less total water-use, although indoor water-use is similar to other locations.

Regression analysis results from households show that hot water-use and water heater characteristics are the main drivers of energy consumption, but outside and inlet temperatures also are important in energy consumption: even though the average indoor water-use in southern California households is larger, northern households use slightly more water-related energy due to lower winter temperatures.

Interestingly although electric water heaters are more efficient heating water than gas-fired heaters, the overall performance comparison depends on the main energy source of electricity generation. Electricity generation using natural gas in a combined plant could have a loss of two thirds of the main energy source including efficiency in generation and distribution losses when the electricity is used in a house. But most electric utilities have a diversified portfolio to generate electricity, so this variability in electric generation has to be considered in overall performance. We included this point using different emission factors for natural gas and electric water heaters, but as most water heaters in California are gas-fired, the effect on final results is tiny. This should not have to be the case in other regions with a higher share of electric water heaters, where the main driver of the GHG emission factors will be the energy source of the electric utility.

From the simulation runs we obtain that total water, water-related energy and greenhouse gas emissions savings for each utility depends on conditions of consumption given by technological, behavioral and external factors, whereas household economic benefits from savings rely on the 
water and energy rates of each utility. Water end-uses with a higher share of hot water receive more economic benefit by saving water because of the reduced energy cost. On the other side, technology or behavior improvements that only affect the energy side, i.e. retrofit water heaters or modify the setpoint temperature, lead to economic benefit only by energy savings.

Including energy and $\mathrm{CO}_{2}$ emissions and their costs in the conceptualization of water-use can improve people's knowledge about their actual expenses and environmental footprint, helping to incentivize potential conservation strategies. Moreover, throughout the analysis of spatial variability, we show that water and energy rates, energy sources available for customers and different energy portfolios of power companies can cause high variability in energy, cost and emission results with customers' water-use held constant. Customers' behavior, in reacting to bills and local, regional and national policies, can change outcomes depending on local conditions such as water and energy rates or temperature.

\section{CONCLUSIONS}

A framework is developed to model heterogeneous and geographically variable residential water end-uses, water-related energy consumption and greenhouse emissions while accounting for water and water-related costs to customers.

Using the method, we assessed water and water-related energy and GHG emissions and costs. Outdoor water-use accounts for more than 50 percent of water-use in California but most waterrelated energy and GHG emissions are from shower and faucet end-uses (roughly $80 \%$ of the total). Water-related energy cost represents a third of water cost in northern cities whereas in much less representative in the south. This is partially due to large water consumption and higher water prices in southern California, but also because outside and inlet temperatures play an important role in reducing energy consumption. 
Include avoided energy cost can increase the proneness to water conservation. For energyintensive appliances — faucet, shower, bath and dishwasher - water and energy costs of use are similar. Inlet temperature plays an important role in water-related energy consumption, what open the possibility for utilities to efficiently manage water supply from different sources to reduce energy consumption in households.

Heterogeneity among households in water and water-related energy and GHG emissions is significant. So selective options targeting high-use households and effective conservation policies - outdoor uses for water, and faucet and shower end-uses for energy consumption and $\mathrm{CO}_{2}$ reductions - have high potential for cost-effective water, energy and $\mathrm{CO}_{2}$ emission savings. Residential water-related carbon footprint depends both on household water heater performance and on the electric generation portfolio of the regional utility. Water-related $\mathrm{CO}_{2}$ emissions average about $730 \mathrm{~kg} /$ year per household, representing $2 \%$ of per capita greenhouse gas emissions in California. This result does not include other embedded energy in water supply, conveyance, treatment, pumping or wastewater collection and treatment. Therefore, total energy and GHG emissions related with residential water-use would be larger, a study being conducted as an extension of this research.

Assessments of residential water-related energy conservation also can vary for different planning scales. From a state perspective, managing water and water-related energy jointly can reduce greenhouse gas emissions significantly in California. For water and energy utilities, joint water and energy conservation programs could reduce the net cost of some strategies as retrofit campaigns or managing energy peaks and reducing carbon footprint. This is a motivation to give users incentives to save water, energy and per capita carbon footprint and to reduce their water and energy bills simultaneously. 


\section{CORRESPONDING AUTHOR}

* Phone: (530) 400-9656; e-mail: alesbou@gmail.com; Mail address: Center for Watershed Sciences. Watershed Sciences Building, $1^{\text {st }}$ Floor. University of California, Davis. One Shields Avenue. Davis, California, 95616. USA.

\section{ACKNOWLEDGEMENTS}

This paper has been developed as a result of a mobility stay funded by the Erasmus Mundus Programme of the European Commission under the Transatlantic Partnership for Excellence in Engineering - TEE Project. The study has been partially supported by the Plan Nacional I+D+I 2008-2011 (Ministry of Science and Innovation, Spain), projects CGL2009-13238-C02-01 and CGL2009-13238-C02-02.

The authors would like to thank Peter Mayer at Aquacraft Inc. for sharing the water end-use dataset and Jim Lutz for his kind attention and clarifications about the WHAM equation.

Finally we would like to express our sincere gratitude to two anonymous reviewers that have contributed to the improvement of the contributions of this paper.

\section{REFERENCES}

Abdallah, A., Rosenberg, D., 2014. Heterogeneous Residential Water and Energy Linkages and Implications for Conservation and Management. J Water Res Pl 140, 288-297.

Arbués, F., García-Valiñas, M.a.Á., Martínez-Espiñeira, R., 2003. Estimation of residential water demand: a state-of-the-art review. The Journal of Socio-Economics 32, 81-102.

Beal, C.D., Bertone, E., Stewart, R.A., 2012. Evaluating the energy and carbon reductions resulting from resource-efficient household stock. Energy Buildings 55, 422-432.

Cahill, R., Lund, J.R., DeOreo, B., Medellin-Azuara, J., 2013. Household water use and conservation models using Monte Carlo techniques. Hydrol Earth Syst Sc 17, 3957-3967. 
CEC, 2005. California's Water - Energy Relationship. Prepared in Support of the 2005 Integrated Energy Policy Report Proceeding. California Energy Commission. November 2005. CEC-7002005-011-SF.

CRPUW, 2009. Power/Utility Reporting Protocol (PUP). The California Registry Power/Utility Workgroup. Available at http://www.climateregistry.org/tools/protocols/industry-specificprotocols/power-utility.html. Accessed 4/14/2014.

DeOreo, W.B., Heaney, J.P., Mayer, P.W., 1996. Flow trace analysis to assess water use. J Am Water Works Ass 88, 79-90.

DeOreo, W.B., Mayer, P.W., Martien, L., Hayden, M., Funk, A., Kramer-Duffield, M., Davis, R., 2011. California single-family water use efficiency study. Aquacraft, Inc. Water Engineering and Management. July 20, 2011.

DOE, U., 2009. Energy efficiency standards for Pool Heaters, Direct Heating Equipment and Water Heaters (EE-2006-STD-0129). Energy Efficiency and Renewable Energy Office (EERE). U.S. Department of Energy (DOE). Available at http://www.regulations.gov/\#!documentDetail;D=EERE-2006-STD-0129-0170. Accessed $4 / 14 / 2014$.

EIA, U., 2009. Residential Energy Consumption Survey 2009. U.S. Energy Information Administration. Available at http://www.eia.gov/consumption/residential/index.cfm. Accessed $4 / 14 / 2014$.

EIA, U., 2011. Voluntary reporting of greenhouse gases program (Voluntary reporting of greenhouse gases program fuel carbon dioxide emission coefficients). U.S. Energy Information Administration. Available at http://www.eia.gov/oiaf/1605/coefficients.html. Last updated January 31, 2011. Accesed 4/14/2014.

Fidar, A., Memon, F.A., Butler, D., 2010. Environmental implications of water efficient microcomponents in residential buildings. Sci Total Environ 408, 5828-5835. 
Kenway, S.J., Scheidegger, R., Larsen, T.A., Lant, P., Bader, H.P., 2013. Water-related energy in households: A model designed to understand the current state and simulate possible measures. Energ Buildings 58, 378-389.

Lutz, J., Whitehead, C.D., Lekov, A., Winiarski, D., Rosenquist, G., 1998. WHAM: A Simplified Energy Consumption Equation for Water Heaters. (3AD). WHAM: A Simplified Energy Consumption Equation for Water Heaters. Proceedings of the ACEEE 1998 Summer Study on Energy Efficiency in Buildings, 1. Washington, DC: ACEEE. .

Mayer, P.W., deOreo, B., Towler, E., Lewis, D.M., 2003. Residential indoor water conservation study: Evaluation of high efficiency indoor plumbing fixture retrofits in single-family homes in the East Bay Municipal Utility District service area. East Bay Municipal Utility District (EBMUD) and The United States Environmental Protection Agency (USEPA). July 2003.

Reffold, E., Leighton, F., Choufhoury, F., Rayner, P., 2008. Greenhouse gas emissions of water supply and demand management. Science Report No SC070010. Environment Agency; 2008.

Rosenberg, D.E., 2007. Probabilistic estimation of water conservation effectiveness. J Water Res Pl-Asce 133, 39-49.

Smirnov, N., 1948. Table for Estimating the Goodness of Fit of Empirical Distributions. Ann Math Stat 19, 279-279. 

Supplementary Material
Click here to download S

Click here to download Supplementary Material: 150310_Modeling residential WECO2 in CA_EnvSciPol SupportinglnfRev02.doc Click here to download Supplementary Material: 150310_Modeling residential WECO2 in CA_EnvSciPol SupportinglnfRevO2.doc (15) soc doc doc doc doc .

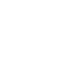

